\title{
Os Adolescentes e a Violência na Imprensa ${ }^{1}$
}

\author{
Maria de Fátima de Souza Santos ${ }^{2}$ \\ Universidade Federal de Pernambuco \\ Renata Lira dos Santos Aléssio \\ Université de Provence \\ Juliana Maria Moura do Nascimento Silva \\ Universidade Federal de Pernambuco
}

\begin{abstract}
RESUMO - O estudo da violência desperta o interesse da sociedade face ao crescimento e ao engajamento de adolescentes de camadas sociais variadas como vitimas ou agentes de violência. O objetivo deste trabalho é analisar as representações sociais sobre adolescência e violência veiculadas pela imprensa pernambucana. Foram analisadas 1.270 notícias publicadas durante 12 meses em dois jornais de Pernambuco. A análise realizada pelo software ALCESTE evidenciou tratamentos diferentes nas reportagens de acordo com a camada social do adolescente. A violência ligada aos jovens de camadas favorecidas aparece como uma tragédia familiar que merece o engajamento das instituições na sua elucidação. Existe uma concretização da violência em um grupo social: os pobres. O binômio violência - pobreza aparece assim reforçado.
\end{abstract}

Palavras-chave: adolescência; violência; representações sociais; imprensa.

\section{Adolescents and Violence in the Press}

\begin{abstract}
The study of violence wakes up the society interest on its growth and also on the engagement of adolescents from several socio-economic strata in violent acts, as victims or as agents of the violence. The objective of this work is to analyze the social representations on adolescence and violence in the newspapers of Pernambuco. We analyzed 1.270 news published during 12 months in two newspapers. The data analyzed by the ALCESTE software shows different treatments in the news, according to the adolescent's social class. Violence related to the upper-class-adolescent is highlighted as a family tragedy which deserves the engagement of the institutions in order to solve it. There is a concretization of the violence in a precise social group: the poor one. Consequently, the binomial violence - poverty is reinforced.
\end{abstract}

Keywords: adolescence; violence; social representations; press.

O objetivo deste trabalho é analisar as representações sociais sobre os adolescentes e a violência na imprensa escrita de Pernambuco. Atualmente, a imprensa desempenha um papel importante na organização e construção das informações que permitem a emergência de teorias do senso comum a respeito dos diferentes objetos sociais.

A violência, como objeto social, está ligada a uma rede de significações, valores, crenças e normas que orientam as práticas sociais dos indivíduos. Segundo alguns autores (Abramovay \& Rua, 2002; Faleiros, 1998; Velho, 1996), a pobreza e as más condições de vida, consideradas isoladamente, não podem explicar a violência. Nesse sentido, é preciso analisar o papel que os "fatores simbólicos" desempenham na sua determinação.

1 Pesquisa realizada com o apoio financeiro do CNPq e do Programa Institucional de Bolsas de Iniciação Científica da UFPE/CNPq. Trabalho apresentado na Vème Conférence Internationale sur les Représentations Sociales, em Roma, setembro de 2005, com o título de "Les adolescents et la violence dans la presse", como parte da Mesa Redonda 'La jeunesse: qu'est-ce qu'on parle, qu'est-ce qu'ils disent?'Agradecemos a Dra. Ângela Maria de Oliveira Almeida por suas contribuições.

2 Endereço para correspondência: Rua Dr. Genaro Guimarães, 12. Casa Amarela. Recife, PE. CEP 52070-040. Fone: (81) 3268-0145, Fax : (81)2126-8270.E-mail:mfsantos@ufpe.br.
No caso da sociedade brasileira, o que inquieta a população e os cientistas de modo geral é o considerável grau de expressão da violência na atualidade, sobretudo entre os jovens (Adorno, 2002; Lima \& cols., 2002; Pegoraro, 2002).

Definir a violência não é uma tarefa fácil para os pesquisadores, sobretudo pelo fato de que o conceito pode significar fenômenos tão diversos como a criminalidade, a negligência, a humilhação e os insultos. Débardieux e Blaya (2002), entretanto, chamam a atenção para o fato de que seria "um erro fundamental, idealista e anti-histórico crer que definir a violência - ou qualquer outra palavra - consiste em se aproximar o máximo possível de seu conceito absoluto, de uma idéia que permite a ligação perfeita entre palavra e coisa" (p. 19). Os autores ressaltam ainda a necessidade de aceitar o fato que, do ponto de vista científico, nós só podemos ter representações parciais da violência e que os diferentes pontos de vista terminam por oferecer uma pluralidade do conhecimento.

Apesar da ausência de uma definição precisa do conceito de violência, os pesquisadores admitem que se trate de um fenômeno que pode ter diferentes configurações e significações, segundo a cultura e o momento histórico no qual ele se produz (Débardieux \& Blaya, 2002). Considerandose que a violência é um objeto polimorfo e de impacto na 
sociedade, fazendo assim parte do cotidiano das pessoas, pode-se considerá-la como um objeto social que origina representações sociais.

As representações sociais são modalidades de conhecimentos construídos pelo senso comum com a finalidade de apreender uma dada realidade social (Abric, 1994; Jodelet, 1998a; Moscovici, 2000/2003). Nesse sentido, a representação não é simplesmente o reflexo da realidade, mas uma organização significante e socialmente compartilhada, que remete ao mesmo tempo a dois tipos de fatores: contingentes e globais. Os fatores contingentes (as circunstâncias, como afirma Flament, 1989) referem-se à natureza e aos limites da situação, ao contexto imediato, à finalidade da situação. Os fatores globais ultrapassam a situação em si e correspondem ao contexto social e ideológico, ao lugar do indivíduo na organização social, à história do indivíduo e do grupo, às determinações sociais e aos sistemas de valores.

Nos últimos anos, o Laboratório de Interação Social Humana (LabInt) da UFPE vem desenvolvendo, juntamente com a UnB e a UFES, um programa de pesquisa sobre as representações sociais da violência e do desenvolvimento humano, entre pais, professores e adolescentes de camadas socioeconômicas médias e médias altas (Almeida, Santos \& Trindade, 2002). Os diversos resultados obtidos nas pesquisas realizadas pelo grupo (e.g., Espíndula \& Santos, 2004; Santos, Mota, Vasconcelos, Medeiros \& Albuquerque, 2007, Agosto) assinalam a construção de representações sociais da violência ligadas à criminalidade e atribuídas a um grupo social exterior Santos e Aléssio (2006) observaram, em adultos, representações de violência objetivadas no espaço público da rua, ligadas ao medo, à ameaça física e à criminalidade. Os atores da violência seriam pessoas desequilibradas, oriundas de "famílias desestruturadas".

Para os pais, a ameaça que vem do outro se concretiza nos amigos dos adolescentes que podem levá-los ao uso de drogas ilícitas, ao consumo de álcool, à gravidez precoce, enfim, a tudo aquilo que pode romper com os valores morais defendidos pela família. Na escola, os professores atribuem os problemas vividos pelos jovens à incapacidade dos pais de dar educação aos seus filhos e à desestruturação familiar (Santos \& Aléssio, 2006). Para os adolescentes de camadas socioeconômicas médias e altas, a ameaça vem do grupo de pessoas pobres enquanto para adolescentes de camadas socioeconômicas baixas, é o outro "drogado" o causador da violência (Santos, Mota, Vasconcellos, Medeiros \& Albuquerque, 2007)

Pode-se, afirmar que a violência é um fenômeno do qual a mediação simbólica é constitutiva. Nesse sentido, parece pertinente estudar a violência enquanto sistema simbólico complexo no qual um conjunto de atores, representações e práticas entram em interação.

As mídias têm como função produzir, conservar e fazer circular informações. Segundo Njaine e Minayo (2002), as mídias produzem e reproduzem o real, absorvendo o imaginário social e "revestindo-o de uma roupagem especial tecnicamente sofisticada e específica para agradar aos mais diferentes segmentos sociais e aos mais variados gostos" ( $p$. 286). Essa preocupação estética com o formato e com o tipo de linguagem empregada pela imprensa em suas publicações repercute no modo como a sociedade confronta os fenômenos do cotidiano e a forma como ela os interpreta. As abordagens utilizadas nas matérias podem guiar a atenção daquele que recebe a informação para um aspecto qualquer da notícia.

As mídias permitem, assim, que as informações circulem e que elas sejam compartilhadas socialmente, possibilitando a construção e reconstrução de atitudes e representações relativas aos objetos em exposição. As atitudes e os posicionamentos guiam práticas e revelam o prisma por meio do qual olhamos um objeto social determinado.

Nessa perspectiva, podemos, então, nos questionar sobre o conteúdo das representações de violência que circulam nos jornais. A violência é tratada do mesmo modo quando os agentes ou vítimas (no caso, os adolescentes) são de camadas socioeconômicas diferentes? Diante de tal questão, propomos como objetivo deste trabalho identificar as representações sociais de adolescentes e de violência que circulam na imprensa escrita de Pernambuco.

\section{Método}

Foram analisadas 1.270 matérias publicadas durante 12 meses (dezembro de 2003 a dezembro de 2004), nos três jornais de maior circulação do estado de Pernambuco. Todas as matérias selecionadas eram relativas a situações de violência envolvendo jovens e adolescentes, entre 12 e 18 anos, tanto na posição de agressores, como na de vítimas de violência.

Os dados foram todos coletados por meio eletrônico, utilizando-se as palavras-chave jovem, adolescente, violência e violento. No caso de um dos jornais, alguns meses ainda não estavam informatizados no momento da coleta. Entramos, então, em contato com a Auçuba/Rede ANDI, que nos permitiu o acesso aos dados já informatizados disponíveis em seus arquivos. Procedemos, inicialmente, à leitura e seleção das matérias pertinentes ao objetivo em questão. Em seguida, foi efetuada a análise das representações divulgadas pela imprensa escrita sobre o adolescente e a violência, focalizando, sobretudo, o modo com que a imprensa aborda o tema e o adolescente, o perfil do adolescente envolvido em situações de violência e a natureza das infrações cometidas.

\section{Análise de dados}

Foi utilizada a análise de conteúdo automática com a ajuda do software ALCESTE (Analyse de Lexèmes Concurrent dans les Ennoncés Simples d'un Texte), elaborado por Reinert (1990). O ALCESTE, a partir da análise da relação entre as palavras presentes no corpus do discurso dos indivíduos (pelo cálculo do $\chi^{2}$ ), permite a construção de classes imbricadas de palavras. Essas palavras se constituem no "material bruto" da análise qualitativa feita pelo pesquisador no momento de recuperar o significado das palavras no corpo do discurso dos indivíduos (contexto). Assim, além das palavras indicadas em cada classe, o pesquisador pode recuperar os trechos dos discursos em que tais palavras foram utilizadas, buscando assim compreender o seu significado. 
Quadro 1. Classificação hierárquica descendente.

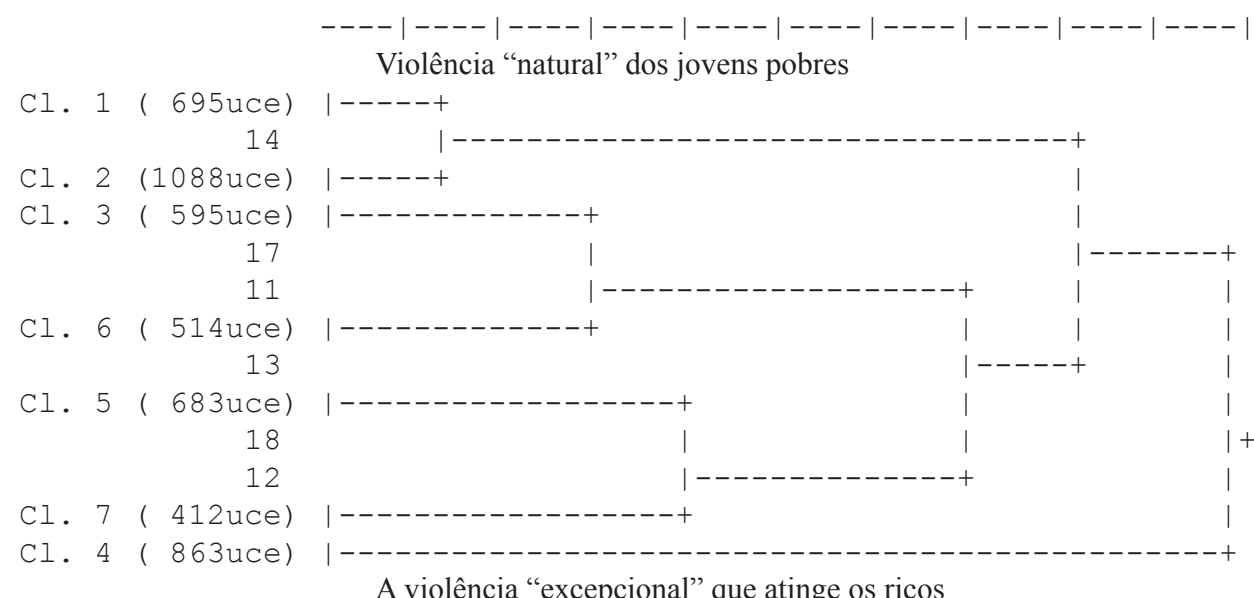

\section{Resultados}

A Classificação Hierárquica Descendente, realizada pelo ALCESTE, permitiu destacar sete classes de palavras representadas no dendrograma abaixo (Quadro 1).

A análise do dendrograma destacou dois diferentes eixos: um eixo que contém apenas a classe quatro e o segundo eixo formado por todas as outras classes decorrentes da análise do ALCESTE (Quadro 2).

\section{Primeiro eixo: a violência "excepcional" que atinge os ricos}

A Classe 4 (O caso Serrambi) reúne todos os conteúdos divulgados pela imprensa escrita a respeito de um só crime acontecido em maio de 2003 em uma praia do litoral sul, a $80 \mathrm{~km}$ de Recife. Esse crime vitimou duas adolescentes de 15 anos originárias de famílias muito ricas de Pernambuco.
Apesar das circunstâncias trágicas e do mistério ligados ao crime, na medida em que ele envolve cenas de personagens de camadas economicamente altas da sociedade, foi observada uma acentuada mobilização da imprensa (um ano após o crime ele é ainda um dos conteúdos mais frequentes), destacando-se personagens da cena política (governador, por exemplo) e instituições locais e federais que tentam explicar e resolver o caso (GOE, Polícia Federal-PF, Instituto de Criminalística-IC, Justiça, Ministério e Universidade). Os sobrenomes de pessoas das famílias das vítimas (Alzira, Gusmão, Dourado), assim como os nomes das vítimas (Eduarda e Tarsila) personalizam os atores e lhes dão uma identidade.

As reportagens descrevem o desaparecimento das meninas em uma praia do litoral sul, os sentimentos de preocupação e de aflição de suas famílias, a aparição dos corpos, a busca da polícia para encontrar os culpados, a tristeza e a perda das famílias e amigos diante de suas mortes. O que nos chama a atenção é o fato de que as adolescentes são apresentadas

Quadro 2. Distribuição de algumas palavras que caracterizam as classes.

\begin{tabular}{|l|l|l|l|l|l|l|}
\hline Classe 1 & Classe 2 & Classe 3 & Classe 4 & Classe 5 & Classe 6 & Classe 7 \\
\hline $\begin{array}{l}\text { O jovem descrito } \\
\text { pela família }\end{array}$ & $\begin{array}{l}\text { O combate à } \\
\text { violência }\end{array}$ & $\begin{array}{l}\text { A ação da polícia } \\
\text { sobre os menores }\end{array}$ & O caso Serrambi & Os crimes & $\begin{array}{l}\text { Os assaltos } \\
\text { aos ônibus }\end{array}$ & A ajuda médica \\
\hline Afirmou & Brasileiro & Adolescente & Alzira & Aconteceu & Assalto & Atingido \\
\hline Apesar & Capital & Apreendido & DNA & Assassino & Celular & Baleado \\
\hline Certeza & Combate & Autuado & Dourado & Bar & Empresa & Cabeça \\
\hline Filho & Estudo & Calibre & Governador & Casa & Ladrão & Hospital \\
\hline Filha & Juventude & DPCA & GOE & Crime & Motorista & Médico \\
\hline Gente & Metropolitana & Enviado & IC & Desconhecido & Onibus & Onde \\
\hline Jamais & Pernambuco & Flagrado & Ministério & Executado & Relógio & Perna \\
\hline Meu & Região & Menor & PF & Local & Veículo & Socorrido \\
\hline Sabemos & Recife & Porte & Serrambi & Morava & & \\
\hline Minha & Situação & Revólver & Tarsila & Morto & & \\
\hline
\end{tabular}


com seus nomes de família, prenomes, as reportagens trazem os discursos dos pais, amigos, o que suscita sentimentos de compaixão, revolta e indignação diante da morte das duas jovens de "boas famílias", belas e ricas. O desenvolvimento do caso atinge ministros, secretários de Estado, juízes e o governador que exigem respostas e a solução de um caso que mobilizou a opinião pública.

O Ministro avaliou a demanda do governador segunda-feira. Há um documento que solicita que a polícia federal fique responsável pelo caso Serrambi.

Segunda, o secretário de Defesa Social, João Braga, solicitará à juíza Ildete Veríssimo uma cópia do relatório assinado pelos médicos legistas.

O caso Serrambi, nome dado pela imprensa, teve uma grande repercussão no país, o que se justifica pela crueldade do crime. Entretanto, nesse mesmo período, dois outros crimes com a mesma crueldade, atingindo também adolescentes - pobres - do sexo feminino, não tiveram a mesma repercussão que o assassinato de Tarsila e Eduarda.

Um ano após o caso, a imprensa trazia notícias com novos questionamentos, suposições e novas investigações sobre o caso Serrambi.

A juiza deu autorização para fazer o teste de DNA nos restos mortais de Tarsila.

\section{Segundo eixo: a violência "natural" dos jovens pobres}

O segundo eixo (classes 1, 2, 3, 5, 6 e 7) reúne todos os conteúdos das situações que não tiveram o mesmo impacto social na imprensa. As classes descrevem situações de violência entre jovens pobres. Nesse caso, as quatro classes trazem textos que descrevem a situação de violência de modo quase anônimo, com uma grande riqueza de detalhes do ato violento.

Classe 1: o jovem descrito pela família. A Classe 1 reúne as palavras que caracterizam a descrição do jovem, vítima ou sujeito da violência, feita pela família. Em geral, o jovem é descrito como alguém "bom", "bem comportado", até o momento em que encontra um grupo de amigos ou um(a) namorado(a) que o conduz ao mundo do crime. A família tenta justificar o envolvimento do jovem com o mundo "marginal".

Ele não tinha vícios. Não bebia, não fumava. Henrique morreu inocentemente. Meu filho jamais se juntou com gente " errada”. Seu vício era o bilhar. Era seu único lazer. Não sabemos quem o matou, nem a razão de seu assassinato. Eu espero que a polícia descubra quem fez esta crueldade.

Apesar do pouco contacto que a gente tinha ultimamente, eu sei que ela não tinha mau comportamento. Desde que ela foi viver com esse namorado, nós não sabemos muita coisa da vida dela, conta Anunciação. Entretanto, o tio do namorado disse, ela foi morta por vingança. Quem fez isso queria se vingar do meu sobrinho.

Ela não disse nada porque ela estava bêbada, mas ela nunca bebia. Tenho certeza que ela foi obrigada a beber cachaça, disse a irmã que afirma não saber quem fez essa atrocidade. O pai da menina, o pintor Antonio Bezerra da Silva, 54 anos, saiu do trabalho direto para o hospital quando soube que sua filha foi encontrada.

As descrições não têm o mesmo impacto que as descrições da classe precedente. Não são descritas as consequências do crime para os amigos e para as famílias, assim como não são descritos detalhes que levem o leitor a personificar o jovem vítima da violência. O testemunho da família sobre o passado do jovem que sofreu ou cometeu violência parece ao leitor uma tentativa de justificar a criminalidade do jovem.

Classe 2: o combate à violência. A Classe 2, associada à Classe 1 , reúne palavras que remetem às instituições e às políticas públicas de combate à violência. Nelas, são veiculadas, por exemplo, dados sobre a violência urbana, índices de violência entre os jovens e notícias sobre as instituições de punição à criminalidade.

Os resultados confirmam a gravidade da violência no Estado, principalmente em certos lugares, como por exemplo, a capital, a região metropolitana do Recife e Caruaru onde as taxas de homicídio assumem valores de uma epidemia. O estudo é resultado de uma tese de doutorado de uma pesquisadora da faculdade de ciências médicas de Pernambuco.

... as taxas de mortalidade por violência entre os residentes da capital é de 174, 58 para cada 100 mil habitantes. Uma situação mais grave que aquela revelada pelo estudo da l'UNESCO que colocou Pernambuco como segundo pior estado brasileiro em condições de vida para os jovens.

Classe 3: a ação da polícia sobre os "menores". A classe 3 trata do jovem em conflito com a lei como um criminoso adulto

O adolescente apreendido, j.g.s.r., 14, a foi flagrado no jardim de sua casa tentando esconder uma arma. Com ele, a polícia encontrou um revólver calibre 38 com cinco munições intactas. O adolescente foi enviado ao plantão da diretoria da polícia da criança e do adolescente, DPCA, onde foi autuado em flagrante por porte ilegal de arma e enviado à unidade da Fundação da Criança e do Adolescente, FUNDAC.

Os menores que foram levados à delegacia de proteção à infância e à adolescência, negaram a intenção de realizar o crime. $O$ adolescente de 15 anos que disse ser o dono do revólver será apreendido por porte ilegal de armas e será enviado à Fundação da criança e do adolescente.

A Classe 3 é a única que remete à ideia dos adolescentes como autores da violência. Entretanto, ela destaca as ações da polícia que tiveram "sucesso". Vale ressaltar o fato de que os adolescentes são aqui tratados de modo anônimo, seja como " menor", seja por meio das iniciais de seu nome.

Classe 5: os crimes. Essa classe reúne as palavras que descrevem os crimes de modo geral.

A vítima, Josuel Candido, foi atingida com vários tiros em sua própria casa, durante a noite do último sábado na frente de sua mulher. 
... Os responsáveis pela morte do rapaz, que aconteceu em um bar da Várzea...

O estudante Cléberton Pereira da Silva morreu na travessa do Cajueiro número 3 e seus familiares desconhecem o motivo do crime.

Os crimes são descritos com riqueza de detalhes pelos amigos e familiares que, em geral, estavam presentes no momento e são, portanto, testemunhas da situação de violência.

Classe 6: os assaltos aos ônibus. Essa classe se caracteriza pelas descrições dos assaltos aos ônibus.

Dois homens armados, provavelmente dois adolescentes, segundo a polícia, anunciaram o assalto no meio da viagem e pegaram todo o dinheiro do ônibus, os celulares e os relógios dos passageiros.

Assalto, tiro e morte deixaram os passageiros em pânico. Eles estavam ontem no onibus da empresa $X$, que fazia a linha $Y$, quando perto de $11: 30$ três marginais entraram no veículo e anunciaram o assalto ...

Classe 7: a ajuda médica. A Classe 7 descreve todas as situações que demandaram ajuda médica às vítimas da violência.

Carlos Alberto, 15 anos, foi atingido por uma bala $e$ foi socorrido no hospital $X$ de onde foi transferido ao hospital $Y$. Ele morreu no início da manhã. A segunda vítima atingida por uma bala na cabeça...

Em suma, o segundo eixo salienta todas as notícias que têm relação com os adolescentes pobres. $\mathrm{O}$ formato factual da notícia oferece "objetividade" aos fatos, ao mesmo tempo em que contribui para a sua banalização. A vida e a morte tornamse fatos comuns, às vezes a morte é mesmo "merecida" pelas relações de amizade dos jovens ("Desde que ela foi viver com esse namorado, nós não sabemos muita coisa da vida dela”). Os acontecimentos descritos não engajam ministérios, governadores. Eles não são acontecimentos "excepcionais", são acontecimentos corriqueiros. A imprensa trata os acontecimentos que envolvem as camadas economicamente baixas da população como acontecimentos banais, que merecem a ação da policia e, às vezes, a intervenção médica.

\section{Discussão}

No que se refere ao tratamento da informação pela imprensa, podemos destacar a legitimação das diferenças entre as duas camadas sociais. A violência da classe média/alta é uma violência a qual o jovem é submetido. As notícias salientam a crueldade da violência física que atinge os jovens, a dor da família, a indignação da sociedade, a preocupação das autoridades, a busca dos responsáveis. Do outro lado, no segundo eixo, a violência das camadas pobres. A imprensa destaca os jovens como autores da violência (mesmo quando são vítimas, eles são apresentados como alguém que vivia em "más companhias"). Além disso, os acontecimentos descritos dão destaque ao ato violento, à descrição "objetiva" de assassinatos diversos, sem se debruçar sobre a história dos personagens, a dor da família ou a indignação das pessoas. Fato comum, cotidiano, que legitima a associação pobrezaviolência. A condição de adolescente não é destacada. Eles são descritos como adultos. A palavra "menor" é utilizada, apesar do Estatuto da Criança e do Adolescente (Brasil, 1990). A ideia de "menor" está ancorada no antigo Código de Menores que tratava os problemas dos adolescentes como caso de polícia e não como caso de políticas. A imprensa demonstra uma preocupação com o combate à violência sem discutir as razões desses atos ou as políticas sociais que podem prevenir e proteger os jovens. O discurso de prevenção dá lugar a um discurso de repressão da violência e, por consequência, do adolescente.

Considerando-se dados publicados pela Delegacia de Proteção à Criança e ao Adolescente de PE (DPCA - PE) ${ }^{3}$, entre 2003 e junho de 2004 foram contabilizados 2.750 atos infracionais cometidos por crianças e adolescentes. O número de vitimas, entretanto é aproximadamente o dobro: foram 6.310 denúncias de abusos e violências dos mais variados tipos contra jovens pernambucanos. Em face dessa realidade, a imprensa pernambucana parece veicular uma superestimação da violência praticada pelo adolescente.

Segundo Almeida (2003, Julho), a violência na imprensa parece ser superestimada pela "exploração excessiva que os mass mídia fazem dos crimes violentos, o que legitima a política penal do Estado" (p. 17).

No que concerne às representações sociais - as acusações a um grupo social específico, no caso o grupo dos adolescentes pobres -, é a aplicação correta de uma lei social que determina as desigualdades entre as camadas econômicas, aspecto ideológico das sociedades capitalistas, como afirma Moscovici (1986). Os pobres são violentos, "sem valores morais", logo, são ameaçadores para os mais ricos. Segundo Chauí (1980), um modo de negar a face estrutural da violência é tomá-la como um acontecimento acidental, excepcional. A violência seria, então, uma reação circunstancial dos mais pobres a uma disfunção social, isto é, às desigualdades sociais.

Culpar os pobres parece fundamental na explicação de uma realidade ameaçadora. Segundo Joffe (1994), “o que se busca aqui é o controle e sentido de comunidade através da projeção do medo na realidade externa" (p. 317).

A atribuição de causalidade a outro grupo parece fazer parte do processo de objetivação. A violência é circunscrita ao outro, sua objetivação serve, assim, às necessidades e interesses de um grupo (Jodelet, 1998b). De fato, pelo viés do processo de focalização, certos aspectos do objeto são salientados enquanto outros são negligenciados. Na tentativa de compreender um fenômeno que se alastra socialmente e torná-lo familiar, a imprensa objetiva a violência em um grupo determinado. Entretanto, é importante ressaltar que não é qualquer lugar, qualquer grupo o escolhido.

O conteúdo da imprensa demonstra que o grupo escolhido para objetivar a violência é justamente o grupo minoritário da sociedade. Desse modo, o conteúdo da representação social que circula na imprensa legitima as relações sociais de desigualdade e naturaliza o binômio pobreza-violência.

3 http://br.geocities.com/dpca2000/principal.htm 
Se, de um lado, essa atribuição serve para manter a identidade grupal das camadas médias - "meu-grupo-não", tal como Joffe (1994) demonstrou no caso da AIDS -, por outro, serve também para legitimar uma ordem social anterior.

A violência é algo que ameaça, provoca medo, angústia. Afastá-la do meu grupo é uma forma de protegê-lo, de me proteger. O outro é, portanto, a causa da violência e eu, o meu grupo, a sua vítima. "Nesse sentido pode-se dizer que o grupo exprime seus contornos e sua identidade pelos sentidos dos quais ele investe sua representação" (Jodelet, 1998b, p. 376). Diante de um objeto ameaçador, concretizálo e circunscrevê-lo em espaço e grupos distintos dos meus ameniza o medo e protege a integridade e identidade grupal. Como afirma Joffe (1994,), "mudanças no ambiente social produzem insegurança, que por sua vez exacerba conflitos de identidade não resolvidos" (p. 315)

Além disso, esse sistema de representações torna-se um código comum, "ele vai servir para classificar os indivíduos e os outros grupos serão avaliados ou posicionados. Ele torna-se instrumento referencial permitindo comunicar na mesma linguagem" (Jodelet, 1998b, p. 377).

Finalmente, é importante observar que o grupo escolhido para representar a violência tem um sentido que é dado a partir de teorias implícitas a respeito do outro, de preconceitos existentes, de relações intergrupais que terminam por mediar a informação que circula na imprensa.

\section{Referências}

Abric, J-C. (1994). Pratiques sociales et représentations. Paris: P.U.F.

Abramovay, M., \& Rua, M. G. (2002). Violências nas escolas. Brasília: UNESCO.

Adorno, S. (2002). Exclusão socioeconômica e violência urbana. Sociologias, 8, 84-135. Retirado em 19/06/2004, de http:// www.scielo.br/soc.

Almeida, A. (2003, Julho). Adolescentes em manchete policial. Trabalho apresentado na III Jornada Internacional e I Congresso Brasileiro sobre Representações Sociais, Rio de Janeiro.

Almeida, A. M. O., Santos, M. F. S., \& Trindade, Z. A. (2002). Representações e práticas sociais. Temas em Psicologia, 8, 257267.

Chauí, M. A. (1980). Não-violência do brasileiro: um mito interessantíssimo. Almanaque: Cadernos de Literatura e Ensaio, $11,16-24$.

Débardieux, E., \& Blaya, C. (2002). Violência nas escolas e politicas públicas. Brasília: UNESCO.

Espíndula, D. H. P., \& Santos, M. F. S. (2004). Representações sobre a adolescência a partir da ótica dos educadores sociais de adolescentes em conflito com a lei. Psicologia em Estudo, 9, 357367.

Brasil (1990). Estatuto da Criança e do Adolescente. Lei $n^{\circ}$. 8.069 de 13 de julho de 1990. Retirado em 15/05/2005, de http:// www.planalto.gov.br/ccivil_03/Leis/L8069.htm.

Faleiros, V. P. (1998). A violência sexual contra crianças e adolescentes e a constituição de indicadores: a crítica do poder, da desigualdade e do imaginário. Ser Social, 2, 37-56.
Flament, C. (1989). Structure et dynanique des représentations sociales. Em D. Jodelet (Org.), Les représentations sociales (pp. 204-219). Paris: PUF.

Joffe, H. (1994). "Eu-não, meu-grupo-não": representações sociais transculturais da Aids. Em S. Jovchelovitch \& P. Guareschi (Orgs.), Textos em representações sociais (pp. 297-322). Petrópolis: Vozes.

Jodelet, D. (1998a) Refléxions sur le traitement de la notion de représentation sociale en psychologie sociale. Communication - Information, VI, 15-41.

Jodelet, D. (1998b). Représentation sociale: Phénomène, concept et théorie. Em S. Moscovici (Org.), Psychologie sociale (pp. 361-382). Paris: Presses Universitaires de France.

Lima, M. L. C., Souza, E. R., Ximenes, R., Albuquerque, M. F. P. M., Bitoun, J., \& Barros (2002). Evolução de homicídios por área geográfica em Pernambuco entre 1980 e 1998 [versão eletrônica]. Revista de Saúde Pública, 36, 462-469.

Moscovici, S. (1986). L'ère des représentations sociales. Em W. Doise \& A. Palmonari (Orgs.), L'Etude des représentations sociales (pp. 34-80). Neuchâtel-Paris: Delachaux \& Niestlé.

Moscovici, S. (2003). Representações sociais (P. A. Guareschi, Trad.). Petrópolis: Rio de Janeiro. (Trabalho original publicado em 2000)

Njaine, K., \& Minayo, M.C. (2002). Análise do discurso da imprensa sobre rebeliões de jovens infratores em regime de privação de liberdade. Ciência e Saúde Coletiva, 7, 285-293.

Pegoraro, J. S. (2002). Notes on youth bearing juvenile violence within post-industrial societies [versão eletrônica]. Sociologias, 8 , 276-317

Reinert, M. (1990). ALCESTE, une méthodologie d'analyse des données textuelles et une application: Aurelia de Gerard de Nerval. Bulletin de Méthodologie, 26, 24-54.

Santos, M. F. S., \& Aléssio R. L. S. (2006). De quem é a culpa? Representações sociais de pais das zonas rural e urbana sobre adolescência e violência. Em A. M. O. Almeida, M. F. S. Santos, G. R. S. Diniz \& Z. A. Trindade (Orgs), Violência, exclusão social e desenvolvimento humano. Estudos em representações sociais (pp. 111 - 134). Brasília: EdUnB.

Santos, M. F. S., Mota, V. L., Vasconcellos, K. M., Medeiros, I. M. S., \& Albuquerque, M. A. (2007, Agosto). Violento é o outro. Estudo de representações sociais da violência entre adolescentes. Trabalho apresentado na V Jornada Internacional e III Conferência Brasileira sobre Representações Sociais, Brasília.

Velho, G. (1996). Violência, reciprocidade e desigualdade: uma perspectiva antropológica. Em G. Velho \& M. Alvito (Orgs), Cidadania e violência (pp. 11-25). Rio de Janeiro: Editora da UFRJ/ Editora da FGV. 